\title{
A New Approach for Wounding Research: MYC2 Gene Expression and Protein Stability in Wounded Arabidopsis Protoplasts
}

\author{
Seungmin Son ${ }^{1,2} \mathbb{D}^{\text {, Miye Kwon }}{ }^{3, *}$ and Jong Hee $\operatorname{Im}^{1,4,5, *}$ \\ 1 Department of Life Sciences, Korea University, 145 Anamro, Sungbuk-gu, Seoul 136701, Korea; \\ linewind@korea.kr \\ 2 National Institute of Agricultural Sciences, Rural Development Administration (RDA), Jeonju 54874, Korea \\ 3 Jeju Biodiversity Research Institute (JBRI), Jeju Technopark (JTP), Jeju 63608, Korea \\ 4 Department of Horticulture, Michigan State University, East Lansing, MI 48824, USA \\ 5 DOE Great Lakes Bioenergy Research Center, Michigan State University, East Lansing, MI 48824, USA \\ * Correspondence: miyekwon@jejutp.or.kr (M.K.); jhim@msu.edu (J.H.I.); Tel.: +82-64-720-2817 (M.K.); \\ $+1-517-353-0458$ (J.H.I.)
}

check for updates

Citation: Son, S.; Kwon, M.; Im, J.H. A New Approach for Wounding Research: MYC2 Gene Expression and Protein Stability in Wounded Arabidopsis Protoplasts. Plants 2021, 10, 1518. https://doi.org/10.3390/ plants10081518

Academic Editor: Anja Schneider

Received: 31 May 2021

Accepted: 23 July 2021

Published: 25 July 2021

Publisher's Note: MDPI stays neutral with regard to jurisdictional claims in published maps and institutional affiliations.

Copyright: (C) 2021 by the authors. Licensee MDPI, Basel, Switzerland. This article is an open access article distributed under the terms and conditions of the Creative Commons Attribution (CC BY) license (https:/ / creativecommons.org/licenses/by/ $4.0 /)$.

\begin{abstract}
Wounding is a constant threat to plant survival throughout their lifespan; therefore, understanding the biological responses to wounds at the cellular level is important. The protoplast system is versatile for molecular biology, however, no wounding studies on this system have been reported. We established a new approach for wounding research using mechanically damaged Arabidopsis mesophyll protoplasts. Wounded protoplasts showed typical wounding responses, such as increased MPK6 kinase activity and upregulated JAZ1 expression. We also assessed expression profiles and protein stability of the basic helix-loop-helix transcription factor MYC2 in wounded protoplasts. Promoter activity, gene expression, and protein stability of MYC2 were compromised, but recovered in the early stage of wounding. In the late stage, the promoter activity and expression of MYC2 were increased, but the protein stability was not changed. According to the results of the present study, this new cell-based approach will be of use in various molecular studies on plant wounding.
\end{abstract}

Keywords: Arabidopsis; LOX2; mesophyll protoplast; MYC2; wounding

\section{Introduction}

Wounding is defined as mechanical damage that occurs frequently in plants due to biotic and abiotic stresses [1]. Plant cells are protected by mechanical barriers, such as cell walls, cuticles, and trichomes; however, such barriers are compromised during wounding, and plant cells show activation of several intracellular signaling mechanisms to heal and protect against wounding [2]. Wounding generates damage-associated molecular patterns and activates MPK6 [3-5]. In addition, the expression of numerous genes associated with phytohormones, oxidative stress, dehydration stress, and heat-shock proteins is rapidly upregulated during wounding [6-8], and protein turnover, transport processes, metabolism modulation, and gene expression reprogramming occur [9].

Jasmonate (JA) is a major immune phytohormone that accumulates after wounding [10]. In Arabidopsis, the basic helix-loop-helix leu zipper transcription factor MYC2 is a major regulator of the JA signaling pathway and response [11]. Further, MYC2 is involved in various phytohormone crosstalk and several signaling pathways [12-14].

Continuous JA signaling is harmful and adversely affects plant growth and development [15]. The JA master regulator MYC2 is a short-lived protein, and its transcriptional activity is regulated by numerous mechanisms [16-18]. MYC2 transcriptional activity and protein stability require tight regulation to optimize plant fitness [19]. In the absence of JA signaling, MYC2 is repressed by a complex consisting of the JASMONATE-ZIM domain 
(JAZ), TOPLESS, and NOVEL INTERACTOR OF JAZ proteins [20-22]. In the presence of JA signaling, MYC2 is derepressed through $\mathrm{SCF}^{\mathrm{COI}}$-dependent degradation of JAZ repressors, and forms a transcriptional activation complex with MEDIATOR25 [23-25]. Thus, JA-triggered activation of MYC2 regulates the transcription of JA-responsive genes, including JAZs and LOX2 [26].

The plant protoplast system has been used as a versatile and powerful complex for cell-based experiments in many plant species [27-29]. The highly efficient protoplast transient expression systems have greatly contributed to the development of various fields of botany, including subcellular localization, protein-protein interaction, transport, signal transduction, and metabolic pathways [30-35]. In particular, transient expression in Arabidopsis mesophyll protoplasts has facilitated advancements in plant research. A recent study reconstituted JA signaling in Arabidopsis protoplasts and confirmed that the protoplast is an invaluable system for functional analysis of signaling components involved in the JA signaling pathway [36].

The protoplast system was previously used to study the effects of various environmental stresses [37]; however, cell-based wounding response methods have not been explored. Here, we analyzed wounding responses in mechanically damaged Arabidopsis mesophyll protoplasts. We further determined MYC2 transcriptional activity and protein stability in these protoplasts. This cell-based study shows wounding response in protoplast cells.

\section{Results}

\subsection{Mechanical Wounding of Arabidopsis Mesophyll Protoplasts}

We first isolated Arabidopsis mesophyll protoplasts (AMPs) and transfected DNA using a previously described method $[28,38]$. Subsequently, the cells were placed in $1.5 \mathrm{~mL}$ tubes at a volume of approximately $1 \mathrm{~mL}$. To induce mechanical damage in AMPs, the transfected cells were vigorously vortexed for $10 \mathrm{~s}$ and were allowed to stand for $10 \mathrm{~min}$ to precipitate at the bottom of the tube. Thereafter, $800 \mu \mathrm{L}$ supernatant was removed from the tube to reduce hypoxia, and the cells were then incubated. After incubation, the supernatant was completely removed, and the cells were harvested (Figure 1).

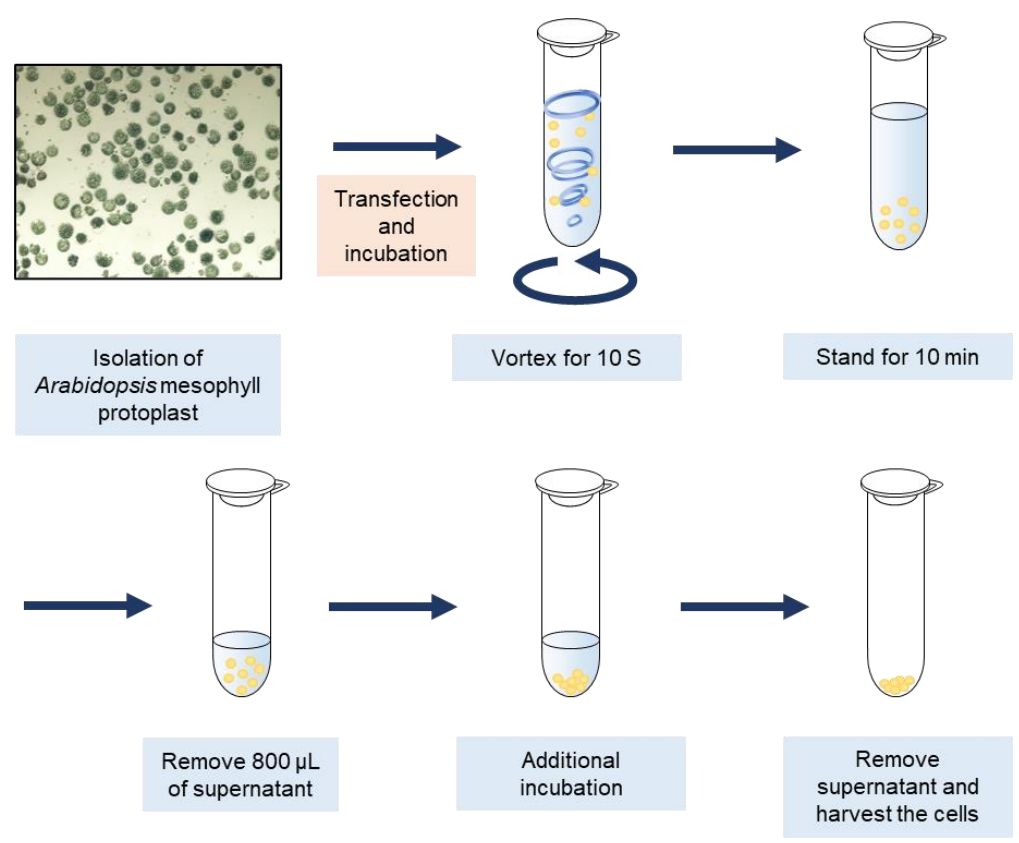

Figure 1. Schematic representation of vortex-induced wounding in Arabidopsis mesophyll protoplasts. Arabidopsis mesophyll protoplast (AMPs) were isolated and transfected with transiently expressing DNA, followed by incubation for desired time. Wounding was induced by vigorous vortexing for $10 \mathrm{~s}$, followed by incubation for $10 \mathrm{~min}$. The supernatant was removed to reduce hypoxia, followed by further incubation. Protoplasts were harvested after the complete removal of the supernatant. 


\subsection{Vortex-Induced Damage Generated Typical Wounding Responses in Protoplasts}

To analyze whether vortex-induced damage would generate wounding responses in AMPs, we distinguished three types of protoplasts based on their shapes: normal shaped cells (NSC), weakly wounded cells (WWC), and severely wounded cells (SWC). NSC had a round shape, and chloroplasts were evenly separated in all cell areas. WWC had a rough cell surface and, even though the cell surfaces were round, chloroplasts were not equally distributed. SWC showed the complete loss of the round shape, and chloroplasts were localized on one side (Figure S1).

We compared the proportions of cell types under normal conditions and after wounding. After transfection of $200 \mu \mathrm{L}$ of AMPs $\left(4-5 \times 10^{4}\right.$ protoplasts in $\left.200 \mu \mathrm{L}\right)$ with $40 \mu \mathrm{g}$ of empty vector, the cells were harvested and wounded through vigorous vortexing at $3200 \mathrm{rpm}$ for 5, 10, 15, and $20 \mathrm{~s}$. In the controls, NSCs accounted for $86.01 \% \pm 3.52 \%$, WWCs accounted for $7.86 \% \pm 0.98 \%$, and SWCs accounted for $6.12 \% \pm 1.38 \%$ of the cells (Figure S2A). However, the composition was significantly altered following wounding. In cells vortexed for $10 \mathrm{~s}$, approximately $70 \%$ of the cells showed altered shapes, and cells vortexed for $15 \mathrm{~s}$ were markedly disrupted (Figure S2A,B).

To verify whether vortex-induced damage would induce a wounding response in the cells, we analyzed MPK6 kinase activity because MPK6 is activated by wounding [39]. After MPK6 was expressed with 355 promoter in AMPs, the cells were vortexed, and MPK6 activity was measured for $60 \mathrm{~min}$. MPK6 activity peaked $20 \mathrm{~min}$ after wounding and decreased thereafter (Figure 2A and Figure S3).

We also analyzed the promoter activity and gene expression of JAZ1 for $60 \mathrm{~min}$ after vortexing because JAZ1 expression is rapidly increased under wounding stress [40]. Promoter activity was not changed in the non-wounded protoplasts, but the promoter activity and expression of JAZ1 were significantly increased following wounding (Figure 2B and Figure S4A); however, the hypoxia marker gene, DIN6, did not change between normal condition and wounding treatment (Figure $2 \mathrm{C}$ and Figure S4B). The data suggest that vortex-induced mechanical damage to protoplasts exhibits typical responses of wounding stress.

\subsection{Gene Expression and Protein Stability of MYC2 Are Compromised and Recovered in Early Stage of Wounding}

JA is a major hormone of the wounding response, and MYC2 is a master regulator of JA signaling [12]. Therefore, we determined the MYC2 promoter activity, gene expression, and protein stability during the early stage of wounding. To analyze the $M Y C 2$ promoter activity, we transfected the fLUC conjugated MYC2 promoter to the AMPs and incubated them for $6 \mathrm{~h}$, then wounded the AMPs by vortexing and incubated the cells for $60 \mathrm{~min}$. MYC2 promoter activity decreased $10 \mathrm{~min}$ after wounding, but recovered quickly and increased for $60 \mathrm{~min}$ after the treatment (Figure 3A). This pattern was correlated with MYC2 gene expression (Figure 3B).

To analyze the transcriptional activity of MYC2 in the wounded protoplasts, we measured LOX2 promoter activity and gene expression caused by direct targeting of MYC2 [41]. The LOX2 promoter activity and gene expression patterns were similar to those of MYC2, but recovery took longer (Figure 3C,D). Therefore, we investigated MYC2 protein stability in wounded protoplasts. C-terminal GFP-conjugated $35 S$ promoter-driven MYC2 DNA was transfected into AMPs and then the protoplasts were wounded for $10 \mathrm{~s}$. The MYC2 protein stability was determined for $60 \mathrm{~min}$. Protein stability was compromised until 20 min after wounding, but increased subsequently (Figure 3E and Figure S5A). MYC2 protein stability was correlated with MYC2-induced LOX2 promoter activity (Figure 3F). The data indicated that MYC2 expression and protein stability were compromised in wounded protoplasts, and then recovered in the early stage. 
A

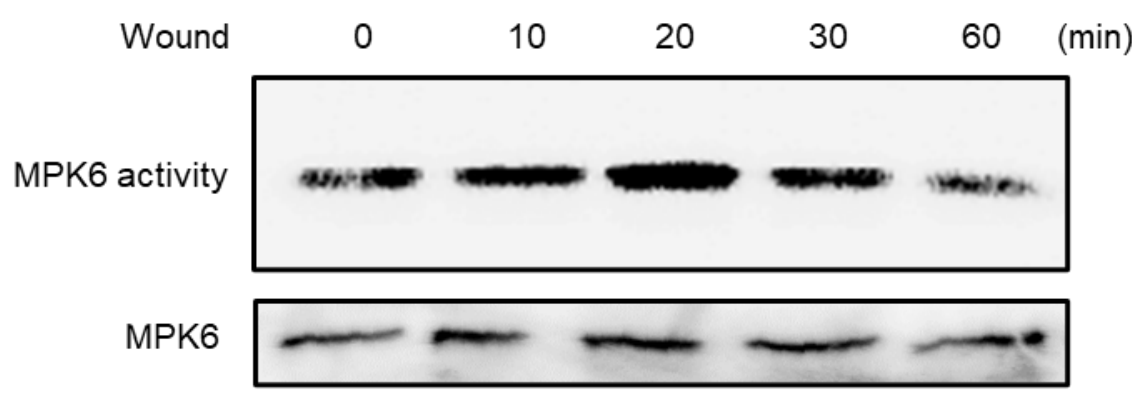

B
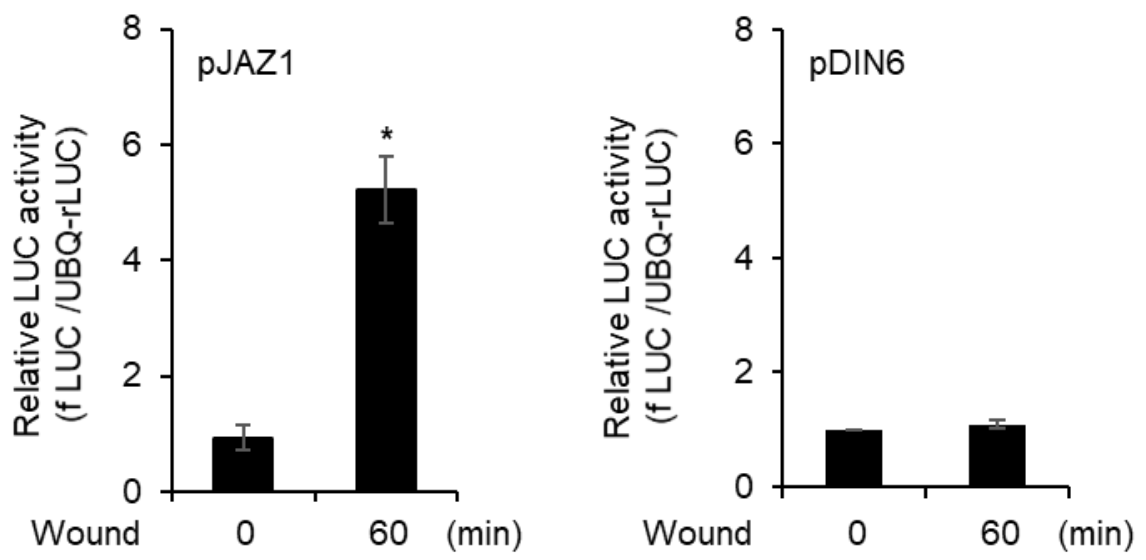

C
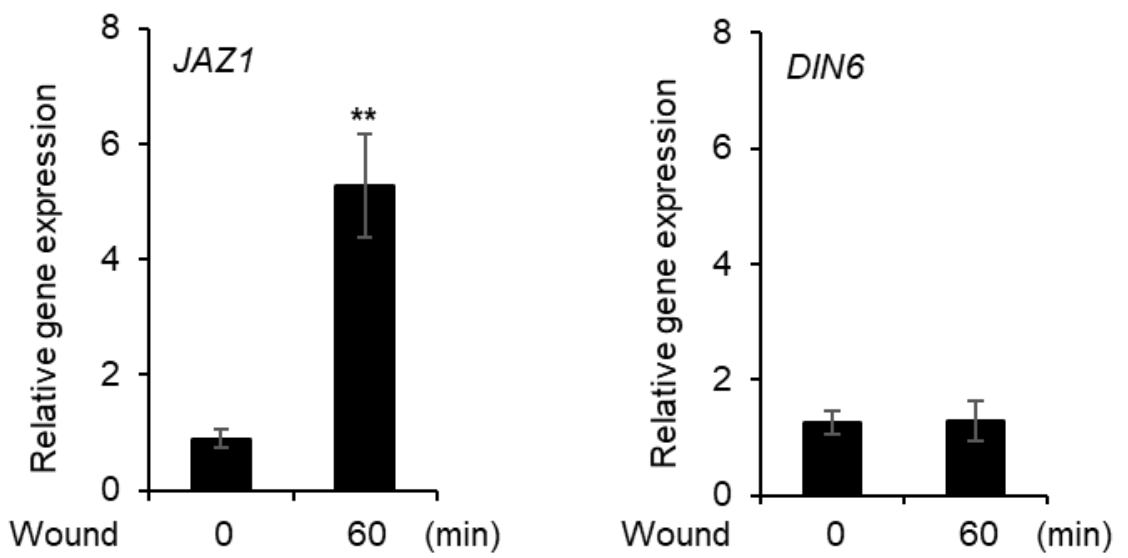

Figure 2. Response of vortex-induced wounding. (A) in vitro kinase activity of MPK6. After MPK6 was expressed in protoplast, vortex-induced wounding was carried out and time-dependent MPK6 activity was determined. Myelin basic protein was used as kinase substrate. The (B) promoter activities of JAZ1 and DIN6 after 60 min of wounding in AMPs. The promoter of JAZ1 and DIN6 was transfected to AMPs and incubated for $6 \mathrm{~h}$. The AMPs were wounded and additionally incubated for $60 \mathrm{~min}$ and promoter activities were analyzed. Values are means $\pm \mathrm{SE}$ of three repeats: ${ }^{*} p<0.01$. The (C) gene expression of JAZ1 and DIN6 in wounded protoplasts. After isolation of AMPs, the protoplasts were incubated for $4 \mathrm{~h}$ without transfection for stabilization and wounded by vortex and incubated for $60 \mathrm{~min}$. Total RNA was isolated from the AMPs and RT-qPCR was carried out. Values are means \pm SE of three repeats: ${ }^{* *} p<0.001$ 
A

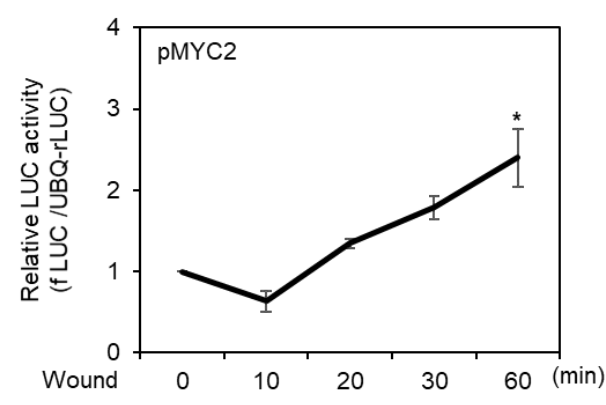

C

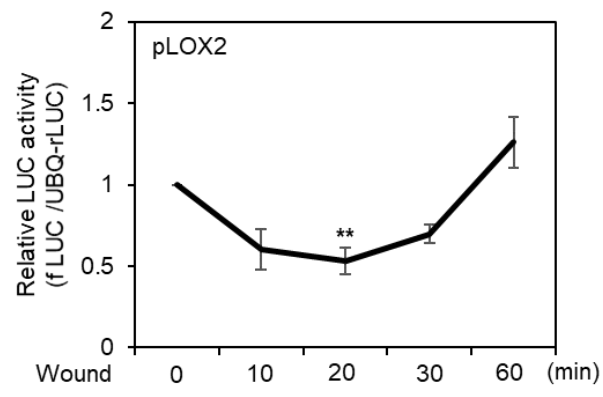

E

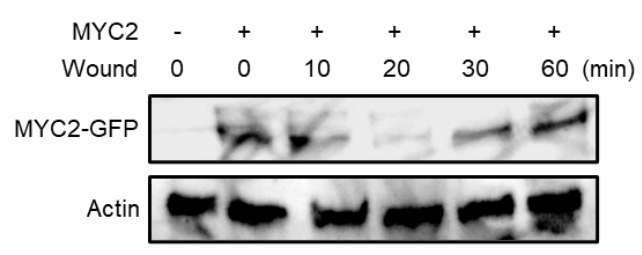

B

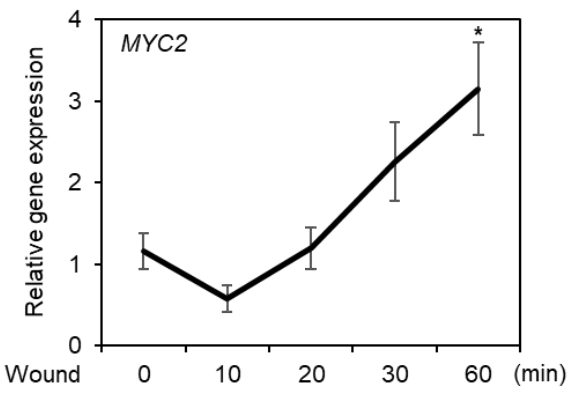

D

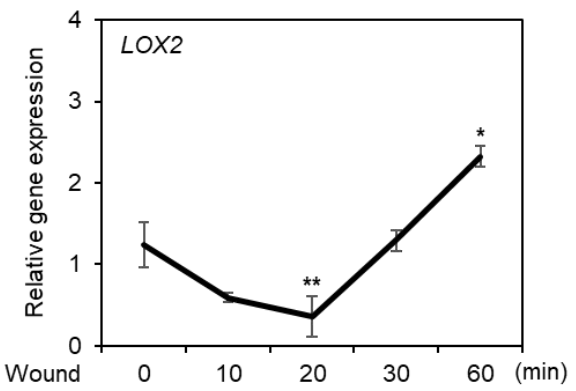

$\mathbf{F}$

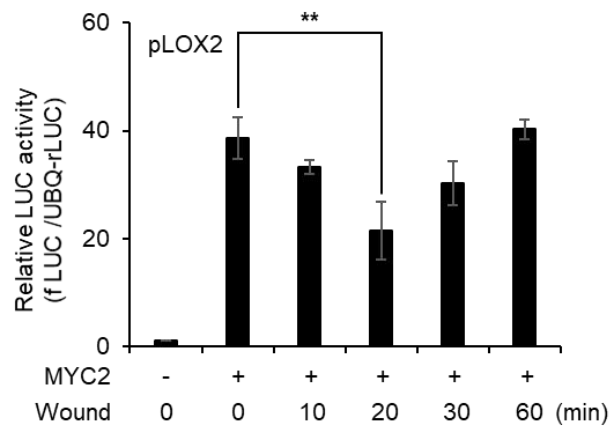

Figure 3. Analysis of promoter activity, gene expression, and protein stability of MYC2 during the early stage of wounding in protoplasts. Promoter activity of MYC2 (A) and LOX2 (C) in the early stage of wounded protoplast. $F L U C$-conjugated MYC2 and LOX2 promoters were respectively transfected to AMPs and incubated for $6 \mathrm{~h}$. Vortex-induced wounding was performed, and the promoter activity was determined in a time-dependent manner. UBQ-rLUC was used as an expression control. Values are means \pm SE of three repeats: ${ }^{*} p<0.01$ and ${ }^{* *} p<0.001$. AMPs were incubated for $4 \mathrm{~h}$ without transfection, wounded by vortex, and incubated for the designated time points. Total RNA was isolated from the AMPs and RT-qPCR was carried out with gene-specific primers of MYC2 (B) and LOX2 (D). Actin2 was used as an expression control. Values are means \pm SE of three repeats: ${ }^{*} p<0.01$ and ${ }^{* *} p<0.001$. (E) Analysis of MYC2 protein stability in wounded protoplasts. $35 S$ promoter-driven C-terminal GFP-conjugated MYC2 was transfected and incubated for $10 \mathrm{~h}$. The protoplasts were wounded and incubated for designated time points and harvested. MYC2 proteins were detected using an anti-GFP antibody. Actin was used as a loading control. (F) Transient promoter activity of LOX2 with MYC2 effector in wounded protoplast. $f L U C$-conjugated LOX2 was expressed with or without MYC2 effector and incubated for $60 \mathrm{~min}$. The LOX2 promoter activity was determined in a time-dependent manner. $U B Q-r L U C$ was used as an expression control. Values are means $\pm \mathrm{SE}$ of three repeats: ${ }^{* *} p<0.001$. 
2.4. Gene Expression of MYC2 Is Increased with Stable Protein Expression at Late Stage of Wounding

We further analyzed MYC2 expression and protein stability over a longer period in wounded protoplasts. The promoter activity and gene expression of MYC2 fluctuated, but showed increasing trends until $6 \mathrm{~h}$ after wounding (Figure $4 \mathrm{~A}, \mathrm{~B})$. The LOX2 promoter activity and gene expression patterns were similar to those of $M Y C 2$ (Figure $4 C, D$ ), suggesting that MYC2 protein stability is not altered in the late stage of wounding.

A

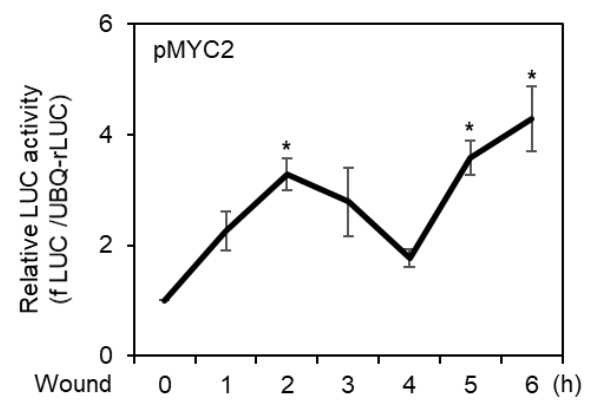

C

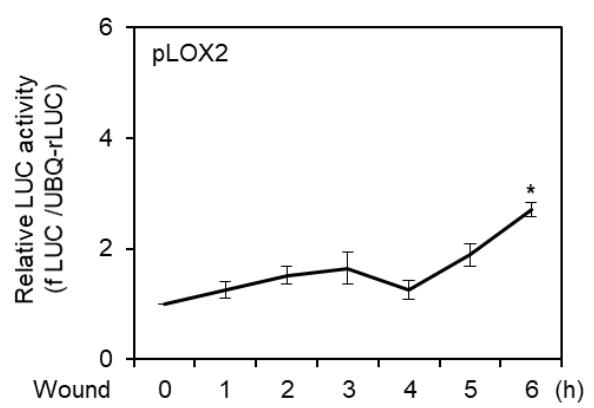

B

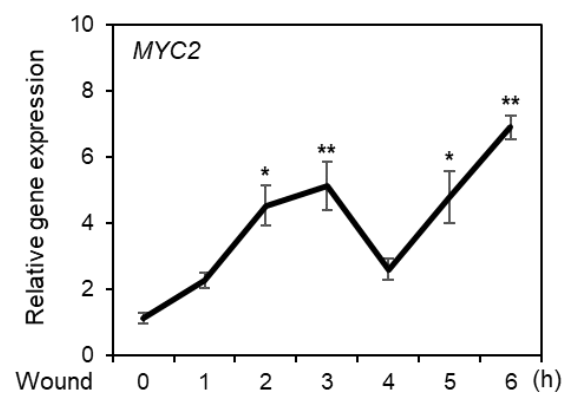

D

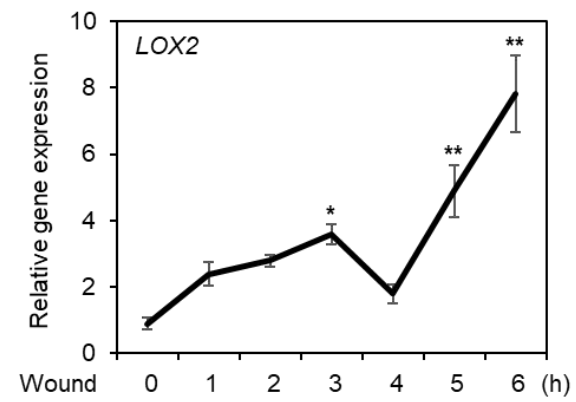

E

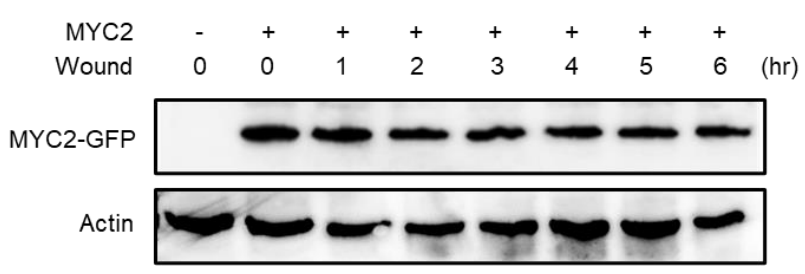

$\mathbf{F}$

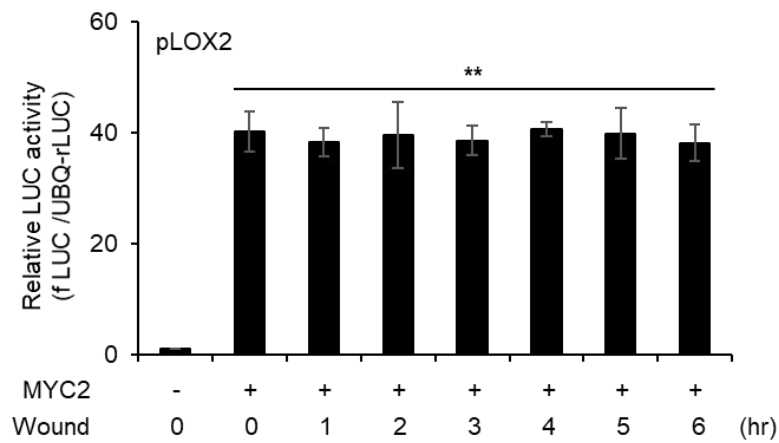

Figure 4. Analysis of promoter activity, gene expression, and protein stability of MYC2 in wounded protoplast at the late stage of wounding. Promoter activities of MYC2 (A) and LOX2 (C) in the late 
stage of wounded protoplast. fLUC-conjugated MYC2 and LOX2 promoters were respectively transfected to AMPs and incubated for $6 \mathrm{~h}$. Vortex-induced wounding was generated in AMPS and incubated for $6 \mathrm{~h}$. The promoter activities were determined in a time-dependent manner. UBQ-rLUC was used as an expression control. Values are means \pm SE of three repeats: ${ }^{*} p<0.01$. AMPs were incubated for $4 \mathrm{~h}$ without transfection and wounded by vortex and incubated for the designated time points. Total RNA was isolated from the AMPs and RT-qPCR was carried out with gene-specific primers of MYC2 (B) and LOX2 (D). Actin2 was used as an expression control. Values are means $\pm \mathrm{SE}$ of three repeats: ${ }^{*} p<0.01$ and ${ }^{* *} p<0.001$. (E) Analysis of MYC2 protein stability in wounded protoplasts. $35 S$ promoter-driven C-terminal GFP-conjugated MYC2 was transfected and incubated for $10 \mathrm{~h}$. The protoplasts were wounded and incubated for designated time points and harvested. MYC2 proteins were detected using an anti-GFP antibody. Actin was used as a loading control. (F) Transient promoter activity of LOX2 with MYC2 effector in wounded protoplast. fLUC-conjugated LOX2 was expressed with or without MYC2 effector and incubated for $6 \mathrm{~h}$. The LOX2 promoter activity was determined in a time-dependent manner. UBQ-rLUC was used as an expression control. Values are means $\pm \mathrm{SE}$ of three repeats: ${ }^{* *} p<0.001$.

To verify the above possibility, we expressed C-terminal GFP-conjugated $35 S$ promoterdriven $M Y C 2$, performed wounding treatments, and then measured MYC2 protein stability for $6 \mathrm{~h}$ in AMPs. As shown in Figure 4E and Figure S5B, the MYC2 protein stability did not change during the $6 \mathrm{~h}$ after wounding. To further verify the stability of MYC2 protein, LOX2 promoter activity was measured. The LOX2 promoter activity increased under MYC2 co-expression, but did not change until after $6 \mathrm{~h}$ of wounding. The results indicated that MYC2 expression increased in the late stage of wounded protoplasts without post-translational modification.

\section{Discussion}

The protoplast system is versatile and has been used for various abiotic stresses but not applied for wounding study $[40,42,43]$. Here, we established a novel method based on Arabidopsis mesophyll protoplasts (AMPs) for analysis of wounding response. We induced mechanical damage to AMPs through vigorous vortexing, which caused damage to all protoplasts and altered the shapes of approximately $66 \%$ of the AMPs. Furthermore, wounding increased MPK6 activity and JAZ1 expression (Figure 2). These effects were typical wounding-induced responses. Consequently, the vortex-induced mechanical damage generates a wounding response in AMPs.

JA is an important hormone of the wounding response, and MYC2 is a key regulator of JA signaling. Therefore, we analyzed MYC2 expression profiles and protein stability in wounded protoplasts. During the early wounding response, MYC2 expression in Arabidopsis leaves was significantly increased at $30 \mathrm{~min}$ and $1 \mathrm{~h}$, and it was decreased $3 \mathrm{~h}$ after wounding [44]. However, earlier responses were not reported. The MYC2 promoter activity and expression were reduced $10 \mathrm{~min}$ after wounding and exhibited rapid recovery (Figure 3A,B). This was a so-far unknown response in wounded cells.

We further analyzed MYC2 gene expression and promoter activity in wounded protoplasts with LOX2. LOX2 promoter activity and gene expression decreased and recovered; however, recovery occurred later than that of MYC2 (Figure 3C,D), indicating that the MYC2 protein is not stable in wounded protoplasts. To verify this possibility, we determined the stability of the MYC2 protein in wounded protoplasts. MYC2 protein was degraded at $20 \mathrm{~min}$ and then recovered (Figure 3E,F). This post-translational modification may be regulated by kinases as numerous kinases are activated during wounding [45-47]. This means that MYC2 may be negatively regulated by one of the activated kinases during early wounding.

Subsequently, we analyzed MYC2 expression and protein stability during the late stage of protoplast wounding. We limited the analysis time to $6 \mathrm{~h}$ after wounding because AMPs turned unstable $24 \mathrm{~h}$ after isolation (Figure S4). MYC2 promoter activity and gene expression increased, and LOX2 exhibited a similar pattern (Figure 4A-D), suggesting that MYC2 is stable in the late stage of wounding, as verified using protein blotting 
of MYC2 (Figure 4E) and by assessing LOX2 promoter activity with MYC2 effector coexpression (Figure $4 \mathrm{~F}$ ). The results indicated that MYC2 expression increased without post-translational modification in the late stage of the wounding.

Wounding treatment of leaves may be associated with a time gap between the first and last treatment, which can be reduced using this protoplast system with vortex-induced wounding. This is an advantage of using vortex-induced wounding.

The novel experimental model outlined in the present study displays the responses of wounded cells, which could be improved by the adoption of a single-cell-based multiomics platform.

\section{Materials and Methods}

\subsection{Plant Material and Growth Conditions}

Arabidopsis thaliana Col-0 plants were used. For protoplast generation, plants were grown in Professional Growth Mix soil (Sun Gro, Agawam, MA, USA) for 23-25 days with programmable light $(12 \mathrm{~h}, 50-70 \mu \mathrm{E})$ and dark $(12 \mathrm{~h})$ conditions at $23^{\circ} \mathrm{C}$. Humidity was adjusted to $40-60 \%$.

\subsection{Protoplast Isolation and Polyethylene Glycol (PEG) Transfection}

Protoplast isolation and polyethylene glycol (PEG)-mediated transfection was performed as described previously [28,38], with slight modifications. Briefly, 24-day-old plants that were grown in soil were cut into small pieces using a razor blade and incubated for $4 \mathrm{~h}$ in an enzyme solution ( $20 \mathrm{mM}$ MES-KOH [pH 5.7], $1.5 \%$ cellulase $\mathrm{R} 10,0.4 \%$ macerozyme R10, $0.4 \mathrm{M}$ mannitol, $20 \mathrm{mM} \mathrm{KCl}$, and $10 \mathrm{mM} \mathrm{CaCl}_{2}$ ). After centrifugation, $4-6 \times 10^{4}$ protoplasts were resuspended in a $200 \mu \mathrm{L}$ MMG solution (4 mM MES-KOH [pH 5.7], $0.4 \mathrm{M}$ mannitol, and $15 \mathrm{mM} \mathrm{MgCl} 2$ ). A total of $20 \mu \mathrm{g}$ of constructs were mixed well with $200 \mu \mathrm{L}$ of protoplasts and a PEG solution (40\% PEG4000, $0.2 \mathrm{M}$ mannitol, and $100 \mathrm{mM} \mathrm{CaCl} 2$ ). After 4 min of incubation, a WI solution (4 mM MES-KOH [pH 5.7], 0.5M mannitol, and $20 \mathrm{mM} \mathrm{KCl}$ ) was added to the sample. The protoplasts were incubated and harvested.

\subsection{In Vitro Kinase Assay}

For the kinase assay, MPK6 was inserted into the HBT promoter and the NOS terminator in the transient expression vector $\mathrm{pHBT}-\mathrm{HA}$. The construct was transfected into mesophyll protoplasts and incubated for the indicated times. The cells were lysed, and the protein extracts were incubated with an anti-HA antibody and the additional adding of A-agarose beads. After bead washing, the immune complex kinase assay of MPK6 was performed as described previously [48]. Briefly, purified MPK6-HA was mixed with $3 \mu \mathrm{g}$ of myelin basic protein in a kinase reaction buffer ( $50 \mathrm{mM}$ Tris- $\mathrm{HCl}$ [pH 7.5], $10 \mathrm{mM}$ $\mathrm{MgCl}_{2}, 1 \mathrm{mM}$ DTT, and $\left.50 \mu \mathrm{M}[\gamma-32 \mathrm{P}] \mathrm{ATP}\right)$ for $30 \mathrm{~min}$ at room temperature. The reaction was stopped by a SDS loading buffer, and an equal volume of each sample was loaded into a 10\% SDS-PAGE gel. After the separating, phosphorylation was detected with a phosphor-image analyzer (FLA-7000, Fujifilm, Japan). The experiment was independently conducted at least three times, and representative data are shown.

\subsection{Transient Promoter Assay}

The protoplast transient promoter assay was performed as described previously [27]. To generate an effector construct for transient expression in protoplasts, MYC2 was cloned into the pHBT-GFP vector. To generate the reporter plasmids, $1 \mathrm{~kb}$ upstream promoter regions of DIN6, LOX2, JAZ1, and MYC2 were cloned into the firefly luciferase vector. For luciferase assays, $8 \mu \mathrm{g}$ of reporter plasmid and $1 \mu \mathrm{g}$ of $p U B Q-r L U C$ [49] were transfected into protoplasts and incubated at $23^{\circ} \mathrm{C}$. After incubation, reporter activities were measured using a dual luciferase assay system (Promega, Madison USA). 


\subsection{RNA Extraction and RT-qPCR}

The isolated protoplasts were incubated at room temperature for stabilization, followed by vortex-induced wounding, and then incubated for the designated period. The total RNA was extracted from the protoplasts using a TRIzol reagent (Invitrogen, Waltham USA), and 200 ng of total RNA was used for the first-strand cDNA synthesis using Superscript III reverse transcriptase (Invitrogen, Waltham USA). A quantitative real-time polymerase chain reaction (RT-qPCR) was performed using specific primers (Table S1) and conducted on the MyiQ Real-Time PCR System (Bio-Rad, Hercules USA) using the SYBR Green Master Mix (Bio-Rad, Hercules USA) under the following conditions: 40 cycles of denaturation at $95{ }^{\circ} \mathrm{C}$ for $10 \mathrm{~s}$, annealing at $58{ }^{\circ} \mathrm{C}$ for $15 \mathrm{~s}$, and extension at $72{ }^{\circ} \mathrm{C}$ for $30 \mathrm{~s}$. The gene expression was quantified using the comparative $\mathrm{Ct}$ method. Actin was used as a calibration control to determine the expression of genes. The experiment was independently conducted at least three times.

\subsection{Protein Blot Analysis}

The total protein was extracted from the protoplasts using an extraction buffer $(50 \mathrm{mM}$ Tris-Base, $150 \mathrm{mM} \mathrm{NaCl}, 10 \mathrm{mM} \mathrm{NaF}, 10 \mathrm{mM} \mathrm{Na}_{3} \mathrm{Vo}_{4}, 1 \times$ Complete, and $0.2 \%$ Triton $\mathrm{X}$ 100). The proteins were separated in 10\% SDS-PAGE and transferred to polyvinylidene difluoride membranes. For immunoblotting, the primary antibodies anti-HA (Roche), anti-GFP (Abcam), and anti-ACT (Agrisera) were used (1:1000). Next, an HRP-conjugated secondary antibody (Abcam) was added $(1: 10,000)$. The signal was detected using an IR-image detector Odyssey (LI-COR, Lincoln USA).

\subsection{Statistical Analyses}

Luciferase assays and RT-qPCRs were independently conducted at least three times, and differences were tested using a t-test in GraphPad Prism 8.0 (GraphPad Software, San Diego, CA, USA).

Supplementary Materials: The following are available online at https://www.mdpi.com/article/10 .3390 / plants10081518/s1, Figure S1: Three different cell types in wounded protoplasts. Figure S2: Proportion of protoplast types and rate of protoplast disruption following vortexing time. Figure S3: Statistical analysis of MPK6 activity in wounded protoplasts. Figure S4: Promoter activities of JAZ1 and DIN6 in normal condition protoplast. Figure S5: Statistical analysis of MYC2 protein stability in wounded protoplasts., Table S1: List of primers of this study.

Author Contributions: Conceptualization, M.K. and J.H.I.; methodology, S. S. and J.H.I.; validation, S.S., M.K., and J.H.I.; formal analysis, S.S. and M.K.; investigation, S.S., M.K., and J.H.I.; resources, J.H.I.; data curation, S.S. and J.H.I.; writing—original draft preparation, J.H.I.; writing-review and editing, S.S., M.K., and J.H.I.; visualization, S.S.; supervision, J.H.I.; project administration, J.H.I.; funding acquisition, M.K. All authors have read and agreed to the published version of the manuscript.

Funding: This research was supported by a National Research Foundation of Korea (NRF) grant funded by the Korean government (MSIT) (2019R1C1C1007725), and the 2021 Post-doctoral Fellowship Program (Project No. PJ01492701) of the National Institute of Agricultural Sciences, Rural Development Administration, Republic of Korea.

Institutional Review Board Statement: Not applicable.

Informed Consent Statement: Not applicable.

Data Availability Statement: The original data are provided in the manuscript.

Conflicts of Interest: The authors declare no conflict of interest.

\section{References}

1. Savatin, D.V.; Gramegna, G.; Modesti, V.; Cervone, F. Wounding in the plant tissue: The defense of a dangerous passage. Front. Plant Sci. 2014, 5, 470. [CrossRef] [PubMed]

2. Leon, J.; Rojo, E.; Sanchez-Serrano, J.J. Wound signalling in plants. J. Exp. Bot. 2001, 52, 1-9. [CrossRef] [PubMed] 
3. Hou, S.; Liu, Z.; Shen, H.; Wu, D. Damage-associated molecular pattern-triggered immunity in plants. Front. Plant Sci. 2019, 10, 646. [CrossRef] [PubMed]

4. Basu, D.; Haswell, E.S. Plant mechanosensitive ion channels: An ocean of possibilities. Curr. Opin. Plant Biol. 2017, 40, 43-48. [CrossRef]

5. Galletti, R.; Ferrari, S.; De Lorenzo, G. Arabidopsis MPK3 and MPK6 play different roles in basal and oligogalacturonide- or flagellin-induced resistance against Botrytis cinerea. Plant Physiol. 2011, 157, 804-814. [CrossRef]

6. Reymond, P.; Farmer, E.E. Jasmonate and salicylate as global signals for defense gene expression. Curr. Opin. Plant Biol. 1998, 1, 404-411. [CrossRef]

7. Reymond, P.; Weber, H.; Damond, M.; Farmer, E.E. Differential gene expression in response to mechanical wounding and insect feeding in Arabidopsis. Plant Cell 2000, 12, 707-720. [CrossRef]

8. Delessert, C.; Wilson, I.W.; Van Der Straeten, D.; Dennis, E.S.; Dolferus, R. Spatial and temporal analysis of the local response to wounding in Arabidopsis leaves. Plant Mol. Biol. 2004, 55, 165-181. [CrossRef]

9. Sozen, C.; Schenk, S.T.; Boudsocq, M.; Chardin, C.; Almeida-Trapp, M.; Krapp, A.; Hirt, H.; Mithofer, A.; Colcombet, J. Wounding and insect feeding trigger two independent MAPK pathways with distinct regulation and kinetics. Plant Cell 2020, 32, 1988-2003. [CrossRef]

10. Glauser, G.; Grata, E.; Dubugnon, L.; Rudaz, S.; Farmer, E.E.; Wolfender, J.L. Spatial and temporal dynamics of jasmonate synthesis and accumulation in Arabidopsis in response to wounding. J. Biol. Chem. 2008, 283, 16400-16407. [CrossRef] [PubMed]

11. Breeze, E. Master MYCs: MYC2, the Jasmonate Signaling “Master Switch". Plant Cell 2019, 31, 9-10. [CrossRef] [PubMed]

12. Kazan, K.; Manners, J.M. MYC2: The master in action. Mol. Plant 2013, 6, 686-703. [CrossRef]

13. Zhu, Z. Molecular basis for jasmonate and ethylene signal interactions in Arabidopsis. J. Exp. Bot. 2014, 65, 5743-5748. [CrossRef] [PubMed]

14. Yang, J.; Duan, G.; Li, C.; Liu, L.; Han, G.; Zhang, Y.; Wang, C. The crosstalks between jasmonic acid and other plant hormone signaling highlight the involvement of jasmonic acid as a core component in plant response to biotic and abiotic stresses. Front. Plant Sci. 2019, 10, 1349. [CrossRef]

15. Huang, H.; Liu, B.; Liu, L.; Song, S. Jasmonate action in plant growth and development. J. Exp. Bot. 2017, 68, 1349-1359. [CrossRef]

16. Zhai, Q.; Yan, L.; Tan, D.; Chen, R.; Sun, J.; Gao, L.; Dong, M.Q.; Wang, Y.; Li, C. Phosphorylation-coupled proteolysis of the transcription factor MYC2 is important for jasmonate-signaled plant immunity. PLoS Genet. 2013, 9, e1003422. [CrossRef]

17. Chico, J.M.; Fernandez-Barbero, G.; Chini, A.; Fernandez-Calvo, P.; Diez-Diaz, M.; Solano, R. Repression of jasmonate-dependent defenses by shade involves differential regulation of protein stability of MYC transcription factors and their JAZ repressors in Arabidopsis. Plant Cell 2014, 26, 1967-1980. [CrossRef] [PubMed]

18. Howe, G.A.; Major, I.T.; Koo, A.J. Modularity in jasmonate signaling for multistress resilience. Annu. Rev. Plant Biol. 2018, 69, 387-415. [CrossRef]

19. Chico, J.M.; Lechner, E.; Fernandez-Barbero, G.; Canibano, E.; Garcia-Casado, G.; Franco-Zorrilla, J.M.; Hammann, P.; Zamarreno, A.M.; Garcia-Mina, J.M.; Rubio, V.; et al. CUL3(BPM) E3 ubiquitin ligases regulate MYC2, MYC3, and MYC4 stability and JA responses. Proc. Natl. Acad. Sci. USA 2020, 117, 6205-6215. [CrossRef]

20. Chini, A.; Fonseca, S.; Fernandez, G.; Adie, B.; Chico, J.M.; Lorenzo, O.; Garcia-Casado, G.; Lopez-Vidriero, I.; Lozano, F.M.; Ponce, M.R.; et al. The JAZ family of repressors is the missing link in jasmonate signalling. Nature 2007, 448, 666-671. [CrossRef] [PubMed]

21. Yan, Y.; Stolz, S.; Chetelat, A.; Reymond, P.; Pagni, M.; Dubugnon, L.; Farmer, E.E. A downstream mediator in the growth repression limb of the jasmonate pathway. Plant Cell 2007, 19, 2470-2483. [CrossRef] [PubMed]

22. Pauwels, L.; Barbero, G.F.; Geerinck, J.; Tilleman, S.; Grunewald, W.; Perez, A.C.; Chico, J.M.; Bossche, R.V.; Sewell, J.; Gil, E.; et al. NINJA connects the co-repressor topless to jasmonate signalling. Nature 2010, 464, 788-791. [CrossRef]

23. Thines, B.; Katsir, L.; Melotto, M.; Niu, Y.; Mandaokar, A.; Liu, G.; Nomura, K.; He, S.Y.; Howe, G.A.; Browse, J. JAZ repressor proteins are targets of the SCF(COI1) complex during jasmonate signalling. Nature 2007, 448, 661-665. [CrossRef] [PubMed]

24. Sheard, L.B.; Tan, X.; Mao, H.; Withers, J.; Ben-Nissan, G.; Hinds, T.R.; Kobayashi, Y.; Hsu, F.F.; Sharon, M.; Browse, J.; et al. Jasmonate perception by inositol-phosphate-potentiated COI1-JAZ co-receptor. Nature 2010, 468, 400-405. [CrossRef]

25. An, C.; Li, L.; Zhai, Q.; You, Y.; Deng, L.; Wu, F.; Chen, R.; Jiang, H.; Wang, H.; Chen, Q.; et al. Mediator subunit MED25 links the jasmonate receptor to transcriptionally active chromatin. Proc. Natl. Acad. Sci. USA 2017, 114, 8930-8939. [CrossRef]

26. You, Y.; Zhai, Q.; An, C.; Li, C. Leunig_Homolog mediates MYC2-dependent transcriptional activation in cooperation with the coactivators HAC1 and MED25. Plant Cell 2019, 31, 2187-2205. [CrossRef] [PubMed]

27. Yoo, S.D.; Cho, Y.H.; Sheen, J. Arabidopsis mesophyll protoplasts: A versatile cell system for transient gene expression analysis. Nat. Protoc. 2007, 2, 1565-1572. [CrossRef]

28. Im, J.H.; Yoo, S.D. Transient expression in Arabidopsis leaf mesophyll protoplast system for cell-based functional analysis of MAPK cascades signaling. Methods Mol. Biol. 2014, 1171, 3-12. [CrossRef] [PubMed]

29. Ren, R.; Gao, J.; Yin, D.; Li, K.; Lu, C.; Ahmad, S.; Wei, Y.; Jin, J.; Zhu, G.; Yang, F. Highly efficient leaf base protoplast isolation and transient expression systems for orchids and other important monocot crops. Front. Plant Sci. 2021, 12, 626015. [CrossRef] [PubMed]

30. Sheen, J. Signal transduction in maize and Arabidopsis mesophyll protoplasts. Plant Physiol. 2001, 127, 1466-1475. [CrossRef] 
31. Goodman, C.D.; Casati, P.; Walbot, V. A multidrug resistance-associated protein involved in anthocyanin transport in Zea mays. Plant Cell 2004, 16, 1812-1826. [CrossRef]

32. Zhang, Y.; Su, J.; Duan, S.; Ao, Y.; Dai, J.; Liu, J.; Wang, P.; Li, Y.; Liu, B.; Feng, D.; et al. A highly efficient rice green tissue protoplast system for transient gene expression and studying light/chloroplast-related processes. Plant Methods 2011, 7, 30. [CrossRef]

33. Hirata, H.; Ohnishi, T.; Ishida, H.; Tomida, K.; Sakai, M.; Hara, M.; Watanabe, N. Functional characterization of aromatic amino acid aminotransferase involved in 2-phenylethanol biosynthesis in isolated rose petal protoplasts. J. Plant. Physiol. 2012, 169, 444-451. [CrossRef]

34. Petersson, S.V.; Linden, P.; Moritz, T.; Ljung, K. Cell-type specific metabolic profiling of Arabidopsis thaliana protoplasts as a tool for plant systems biology. Metabolomics 2015, 11, 1679-1689. [CrossRef] [PubMed]

35. Denyer, T.; Ma, X.; Klesen, S.; Scacchi, E.; Nieselt, K.; Timmermans, M.C.P. Spatiotemporal developmental trajectories in the Arabidopsis root revealed using high-throughput single-cell RNA sequencing. Dev. Cell 2019, 48, 840-852. [CrossRef]

36. Li, N.; Uhrig, J.F.; Thurow, C.; Huang, L.J.; Gatz, C. Reconstitution of the jasmonate signaling pathway in plant protoplasts. Cells 2019, 8, 1532. [CrossRef]

37. Confraria, A.; Baena-González, E. Using Arabidopsis protoplasts to study cellular responses to environmental stress. In Environmental Responses in Plants; Springer: Berlin, Germany, 2016; pp. 247-269.

38. Im, J.H.; Cho, Y.H.; Kim, G.D.; Kang, G.H.; Hong, J.W.; Yoo, S.D. Inverse modulation of the energy sensor Snf1-related protein kinase 1 on hypoxia adaptation and salt stress tolerance in Arabidopsis thaliana. Plant Cell Environ. 2014, 37, 2303-2312. [CrossRef]

39. Li, S.; Han, X.; Yang, L.; Deng, X.; Wu, H.; Zhang, M.; Liu, Y.; Zhang, S.; Xu, J. Mitogen-activated protein kinases and calciumdependent protein kinases are involved in wounding-induced ethylene biosynthesis in Arabidopsis thaliana. Plant Cell Environ. 2018, 41, 134-147. [CrossRef] [PubMed]

40. Chung, H.S.; Koo, A.J.; Gao, X.; Jayanty, S.; Thines, B.; Jones, A.D.; Howe, G.A. Regulation and function of Arabidopsis jasmonate ZIM-domain genes in response to wounding and herbivory. Plant Physiol. 2008, 146, 952-964. [CrossRef] [PubMed]

41. Hou, X.; Lee, L.Y.; Xia, K.; Yan, Y.; Yu, H. DELLAs modulate jasmonate signaling via competitive binding to JAZs. Dev. Cell 2010, 19, 884-894. [CrossRef] [PubMed]

42. Heyer, M.; Reichelt, M.; Mithofer, A. A Holistic approach to analyze systemic jasmonate accumulation in individual leaves of Arabidopsis rosettes upon wounding. Front. Plant Sci. 2018, 9, 1569. [CrossRef]

43. Hoermayer, L.; Montesinos, J.C.; Marhava, P.; Benkova, E.; Yoshida, S.; Friml, J. Wounding-induced changes in cellular pressure and localized auxin signalling spatially coordinate restorative divisions in roots. Proc. Natl. Acad. Sci. USA 2020, 117, 15322-15331. [CrossRef]

44. Zhang, C.; Lei, Y.; Lu, C.; Wang, L.; Wu, J. MYC2, MYC3, and MYC4 function additively in wounding-induced jasmonic acid biosynthesis and catabolism. J. Integr. Plant Biol. 2020, 62, 1159-1175. [CrossRef] [PubMed]

45. Takahashi, F.; Mizoguchi, T.; Yoshida, R.; Ichimura, K.; Shinozaki, K. Calmodulin-dependent activation of MAP kinase for ROS homeostasis in Arabidopsis. Mol. Cell 2011, 41, 649-660. [CrossRef]

46. Ichimura, K.; Mizoguchi, T.; Yoshida, R.; Yuasa, T.; Shinozaki, K. Various abiotic stresses rapidly activate Arabidopsis map kinases ATMPK4 and ATMPK6. Plant J. 2000, 24, 655-665. [CrossRef] [PubMed]

47. Horak, H. Defense, Fast and Slow: Activation of different MAPK pathways in response to wounding. Plant Cell 2020, 32, 1788-1789. [CrossRef]

48. Leissing, F.; Nomoto, M.; Bocola, M.; Schwaneberg, U.; Tada, Y.; Conrath, U.; Beckers, G.J. Substrate thiophosphorylation by Arabidopsis mitogen-activated protein kinases. BMC Plant Biol. 2016, 16, 48. [CrossRef] [PubMed]

49. Cho, Y.H.; Hong, J.W.; Kim, E.C.; Yoo, S.D. Regulatory functions of SnRK1 in stress-responsive gene expression and in plant growth and development. Plant Physiol. 2012, 158, 1955-1964. [CrossRef] [PubMed] 